\title{
TU/e EN⿴HONE

\section{Proton conductive cationic nanoporous polymers based on smectic liquid crystal hydrogen-bonded heterodimers}

\section{Citation for published version (APA):}

Mulder, D. J., Liang, T., Xu, Y., ter Schiphorst, J., Scheres, L. M. W., Oosterlaken, B. M., Borneman, Z., Nijmeijer, K., \& Schenning, A. P. H. J. (2018). Proton conductive cationic nanoporous polymers based on smectic liquid crystal hydrogen-bonded heterodimers. Journal of Materials Chemistry C, 6(18), 5018-5024. https://doi.org/10.1039/c8tc00857d

DOI:

10.1039/c8tc00857d

Document status and date:

Published: $14 / 05 / 2018$

\section{Document Version:}

Accepted manuscript including changes made at the peer-review stage

\section{Please check the document version of this publication:}

- A submitted manuscript is the version of the article upon submission and before peer-review. There can be important differences between the submitted version and the official published version of record. People interested in the research are advised to contact the author for the final version of the publication, or visit the $\mathrm{DOI}$ to the publisher's website.

- The final author version and the galley proof are versions of the publication after peer review.

- The final published version features the final layout of the paper including the volume, issue and page numbers.

Link to publication

\section{General rights}

Copyright and moral rights for the publications made accessible in the public portal are retained by the authors and/or other copyright owners and it is a condition of accessing publications that users recognise and abide by the legal requirements associated with these rights.

- Users may download and print one copy of any publication from the public portal for the purpose of private study or research.

- You may not further distribute the material or use it for any profit-making activity or commercial gain

- You may freely distribute the URL identifying the publication in the public portal.

If the publication is distributed under the terms of Article 25fa of the Dutch Copyright Act, indicated by the "Taverne" license above, please follow below link for the End User Agreement:

www.tue.nl/taverne

Take down policy

If you believe that this document breaches copyright please contact us at:

openaccess@tue.nl

providing details and we will investigate your claim. 


\section{Journal Name}

\section{ARTICLE}

\section{Proton conductive cationic nanoporous polymers based on smectic liquid crystal hydrogen-bonded heterodimers}

Received 00th January 20xx, Accepted 00th January 20xx

DOI: $10.1039 / \times 0 \times x 00000 x$

www.rsc.org/
Dirk-Jan Mulder, ${ }^{\mathrm{a}, \mathrm{e}, \uparrow}$ Ting Liang, ${ }^{\mathrm{a}, \mathrm{b}, \mathrm{c},+}$ Y Yifei Xu, ${ }^{\mathrm{d}}$ Jeroen ter Schiphorst, ${ }^{\mathrm{a}}$ Luc M. W. Scheres, ${ }^{\mathrm{a}, \mathrm{h}}$ Bernette M. Oosterlaken, ${ }^{d}$ Zandrie Borneman, ${ }^{b, g}$ Kitty Nijmeijer, ${ }^{*, b, g}$ Albertus P. H. J. Schenning ${ }^{*, a, f}$

The fabrication of a cationic nanoporous smectic liquid crystal network (LCN) based on hydrogen bonded heterodimers is presented. The method relies on a supramolecular complex made from a pyridyl bearing reactive mesogen hydrogen bonded to a non-reactive benzoic acid template. Upon addition of a cross-linker, a smectic liquid crystalline phase is obtained that can be fixed by photopolymerization. It was found that the lamellar structure was maintained after template removal when 25 wt\% or more cross-linker was used, yielding a nanoporous LCN. After $\mathrm{H}_{3} \mathrm{PO}_{4}$ immobilization in the pores of the LCN, a cationic 2D nanoporous polymer is obtained showing high and anisotropic anhydrous proton conductivity.

\section{Introduction}

Nanoporous polymer materials are of scientific and technological importance because of their large pore surface area to volume ratio and their specific interactions with ions and molecules on the nanometer scale.1,2 This makes these polymers suitable for applications such as separation, catalysis, sensing and conductance. $^{3-6}$ The properties of nanoporous materials depend on the pore size, porosity, pore distribution, pore alignment and pore chemistry. Together these characteristics determine the potential applications. ${ }^{7,8}$ The fabrication of nanoporous materials with tailored pores and programmed properties is, however, still a main challenge. ${ }^{9}$ For example, in the field of proton exchange membrane fuel cells, proton conductive nanoporous membranes that can be applied at intermediate temperatures $\left(120-200{ }^{\circ} \mathrm{C}\right)$ are required while most materials exhibit high performance under humid condition but lose conductivity when the temperature rises above $100{ }^{\circ} \mathrm{C} .{ }^{10,11}$ Therefore, anhydrous proton conductive polymers with ordered protic nanopores are highly demanded. 5,6

a. Department of Functional Organic Materials and Devices, Chemical Engineering and Chemistry, Eindhoven University of Technology, P.O. Box 513, 5600 MB, Eindhoven, The Netherlands.

b. Membrane Materials and Processes, Chemical Engineering and Chemistry, Eindhoven University of Technology, P.O. Box 513, 5600 MB, Eindhoven, The Netherlands.

School of Chemical Engineering, Sichuan University No. 24 South Section 1, Yihuan Road, Chengdu 610065, China.

d. Laboratory of Materials and Interface Chemistry, Chemical Engineering and Chemistry, Eindhoven University of Technology, PO box 513, 5600 MB, Eindhoven, The Netherlands.

e. Dutch Polymer Institute (DPI), PO Box 902, 5600 AZ, Eindhoven, The Netherlands. f. Institute for Complex Molecular Systems (ICMS), Eindhoven University of Technology, P.O. Box 513, 5600 MB, Eindhoven, The Netherlands.

g. Dutch Institute for Fundamental Energy Research (DIFFER), De Zaale 20, 5612 AJ, Eindhoven, The Netherlands.

h. Surfix BV, Bronland 12 B-1, 6708 WH, Wageningen, The Netherlands.

+ Both authors contributed equally to this work.

Electronic Supplementary Information (ESI) available: [details of any supplementary information available should be included here]. See DOI: 10.1039/x0xx00000x
Liquid crystals (LCs) have been proven to be promising candidates for the construction of nanoporous polymer materials with pore dimensions around $1 \mathrm{~nm} \cdot{ }^{12}$ For the construction of these materials, columnar, lamellar and bicontinuous cubic phases have been used leading to $1 \mathrm{D}, 2 \mathrm{D}$ and $3 \mathrm{D}$ nanoporous polymers, respectively. ${ }^{13-15}$ Currently, many of these nanoporous materials are based on hydrogen bonded building blocks where these non-covalent interactions have been used to position a non-reactive template molecule ${ }^{16,17}$ and where polymerization is used to create a network. The non-reactive template acts as a so-called porogen, which after removal creates nanopores with dimensions in compliance with the shape of the template. ${ }^{18-22}$ So far, most of the pores are negatively charged carboxylates and often columnar or cubic phases are used. ${ }^{19,23-26}$ and to date, there is only one example where the templating method has been applied to smectic LC materials yielding $2 \mathrm{D}$ nanoporous polymers with negatively charged pores ${ }^{27}$. For the use in e.g. separation and transport processes, however, it is of upmost interest to fabricate positively charged cationic 2D nanoporous polymers, as this will broaden the range of applications.

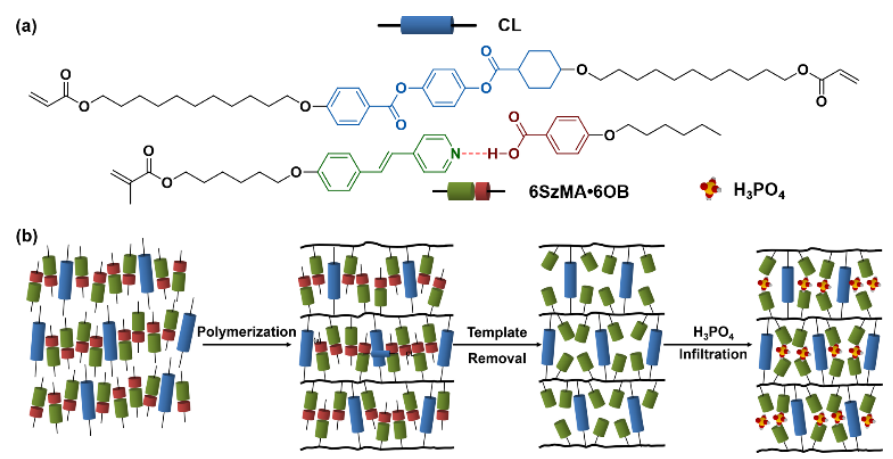

Figure 1 (a) Chemical structures of the monomer mixture containing the hydrogen bonded 6SzMA-6OB complex and the cross-linker (CL). (b) Schematic representation of the fabrication of the cationic nanoporous smectic polymer films from the hydrogen bonded heterodimers and cross-linker. 
In this work, the fabrication of such a positively charged (cationic) nanoporous smectic polymer, based on hydrogen bonded heterodimers using a template method, is reported. This approach relies on a complex made from a pyridyl reactive mesogen (6SzMA) hydrogen bonded to a non-reactive porogen (6OB) and a cross-linker (CL). After cross-linking, upon chemical treatment, the porogen can be removed, resulting in the formation of protic nanopores after acid treatment. When using phosphoric acid the pyridine units are protonated, yielding a highly anisotropic 2D proton-conducting material. 28

\section{Experimental}

\section{Materials}

6-Bromohexan-1-ol (> $95 \%$ ) was obtained from TCl Europe N.V., triethylamine (99\%) was obtained from Acros. Methacryloyl chloride (97\%), 4-methylpyridine (98\%), 4-hydroxybenzaldehyde (98\%), acetic anhydride ( $\geq 99 \%$ ), sodium borohydride ( $>96 \%$ ) and cesium carbonate $(99 \%)$ were obtained from Sigma Aldrich. Cross-linker (CL) trans-4-(4-(11-acryloyloxyundecyloxy) cyclohexanecarboxyloxy) phenyl-4-(11-acryloyloxyundecyloxy) benzoate (Figure 1a) was obtained from Syncom B.V. All solvents used were analytical grade and obtained from Biosolve. Dry ethanol was prepared by storing it overnight over $3 \AA$ molecular sieves (activated in an oven at $600^{\circ} \mathrm{C}$ ). $1 \mathrm{M} \mathrm{HCl}$ (aq.) was freshly prepared from a $37 \% \mathrm{HCl}$ solution obtained from Sigma Aldrich. All reagents were used as received, without further purification.

\section{Synthesis of 4'-(6-methacyloxyhexyloxy-4-stilbazole) (6SzMA)}

The methacrylic 6SzMA monomer was prepared by a 4-step synthesis route (Scheme 1). In the first step (a), 4-acetoxystilbazole (i) was prepared according to the procedure as described by Shaw et al. ${ }^{29}$ and Chiang et al. ${ }^{30}$ It was found that by adding a small amount of $4 \AA$ molecular sieves to the reaction mixture, side reactions were reduced and the yield increased from $30 \sim 40 \%$ to more than $70 \%$. Subsequently, the acetic acid ester $\mathbf{i}$ was hydrolyzed by reflux in ethanolic $\mathrm{KOH}$ yielding 4-hydroxystilbazole (ii, reaction (b)). In parallel, 6-bromohexyloxymethacrylate was prepared by the procedure described by Stumpel et al. ${ }^{31}$ Finally, 6SzMA was obtained by a Williamson ether synthesis (reaction (d)) of ii and iii using cesium carbonate $\left(\mathrm{Cs}_{2} \mathrm{CO}_{3}\right)$ in anhydrous dimethylformamide at room temperature. The synthesis details are given in the supporting information.

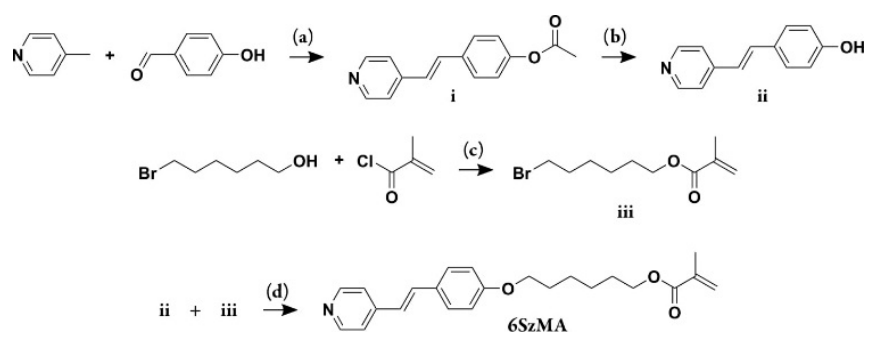

Scheme 1 Synthesis of 6SzMA. (a) $4 \AA$ molecular sieves, $\mathrm{Ac}_{2} \mathrm{O}$, reflux $48 \mathrm{~h}$, Yield: $79 \%$. (b) 1.1 eq. $\mathrm{KOH}$, EtOH, reflux $16 \mathrm{~h}$, Yield: $77 \%$. (c) Triethylamine, $\mathrm{CH}_{2} \mathrm{Cl}_{2}$, $-20{ }^{\circ} \mathrm{C}-$ r.t. 16 h, Yield: $57 \%$. (d) 3 eq. $\mathrm{Cs}_{2} \mathrm{CO}_{3}, 4 \AA$ molecular sieves, DMF, r.t. $24 \mathrm{~h}$, Yield: $86 \%$.

\section{Preparation of the liquid crystal network}

A mixture containing $6 \mathrm{SzMA} \cdot 6 \mathrm{OB}$ and various amounts of $\mathrm{CL}$ was used to prepare LCNs (Figure 1). $1 \mathrm{wt} \%$ photo initiator (Irgacure 819) and $0.5 \mathrm{wt} \%$ thermal inhibitor butylated hydroxytoluene (BHT) were added to perform the photopolymerization. All compounds were dissolved in dichloromethane to obtain a homogeneous mixture. The dichloromethane was removed in vacuum after mixing. $20 \mu \mathrm{m}$ thick films were prepared by capillary suction of the LC-monomer mixture in the melt $\left(125^{\circ} \mathrm{C}\right)$ between two accurately spaced glass slides (LC cell). After filling of the cell, the mixture was cooled to $30{ }^{\circ} \mathrm{C}$. Subsequently, the polymerization was performed by UV irradiation using a EXFO OmniCure ${ }^{\star}$ S2000 spot UV curing lamp for 600 seconds equipped with a $405 \mathrm{~nm}$ cut-off filter. To obtain planar and homeotropic alignment, the glass slides (LC cell) were provided with rubbed polyimide and octadecyltrimethoxysilane, respectively.

\section{OB removal}

Small pieces of pristine 6SzMA•6OB LCN were exposed to a $0.33 \mathrm{mM}$ $\mathrm{KOH}$ solution in a 2:1 tetrahydrofuran (THF)/water mixture overnight under continuous shaking. Subsequently, the films were placed in water to wash off the remaining $\mathrm{KOH}$ (Figure 1b). The films were dried in vacuum prior to further use. To determine the $\mathrm{pH}$ at which the pyridine moieties were protonated the films were immersed in diluted $\mathrm{HCl}$ or citrate buffer, $1 \mathrm{M} \mathrm{NaCl}$ solutions of $\mathrm{pH} 1$ to 6 .

\section{$\mathrm{H}_{3} \mathrm{PO}_{4}$ immobilization}

Nanoporous polymer films ( $25 \% \mathrm{CL}, 6 \mathrm{OB}$ removed) were exposed to a freshly made solution of $0.1 \mathrm{M} \mathrm{H}_{3} \mathrm{PO}_{4}(68 \mu \mathrm{l}$ in $10 \mathrm{ml}$ solvent) and were shaken for 24 hours. Different $\mathrm{H}_{3} \mathrm{PO}_{4}$ occupations were obtained by using different solvents. Occupations of 1.06 equivalents (eq.) or 2.54 eq. $\mathrm{H}_{3} \mathrm{PO}_{4}$ were obtained by using $\mathrm{THF} / \mathrm{H}_{2} \mathrm{O}(5 \mathrm{ml}: 5 \mathrm{ml})$ or pure THF (10 ml) as solvent, respectively. The $\mathrm{H}_{3} \mathrm{PO}_{4}$ immobilized films were washed with ethanol (Figure $1 \mathrm{~b}$ ) and at room temperature vacuum dried before further characterization.

\section{Characterization}

Nuclear magnetic resonance was performed on a $400 \mathrm{MHz}$ Agilent Technologies 400-MR NMR Spectrometer. Infrared spectroscopy was performed on a Varian 670 IR spectrometer equipped with a microscopy setup over a range of $4000-650 \mathrm{~cm}^{-1}$ with a spectral resolution of $4 \mathrm{~cm}^{-1}$ and 100 scans per spectrum. Polarized optical microscopy was performed on a Leica DM 4 P optical microscope equipped with polarization filters. A Linkam TMS 600 hot stage was used for temperature controlled experiments. Differential scanning calorimetry was performed on a TA Instruments Q1000 calorimeter. The samples were heated and cooled with $5^{\circ} \mathrm{C} \mathrm{min}^{-1}$ between $-40^{\circ} \mathrm{C}$ and $130^{\circ} \mathrm{C}$ with an isothermal equilibration of 3 minutes after each heating or cooling ramp. X-ray diffraction experiments were performed on a SAXSLAB GANESHA $300 \mathrm{XL}$ system. UV-Vis spectroscopy experiments were done using a Shimadzu UV-3102 spectrophotometer. Transmission electron microscopy imaging was performed under $2.5 \mu \mathrm{m}$ defocus on a FEI-Titan TEM equipped with a field emission gun (FEG) and operating at $300 \mathrm{kV}$. Images were recorded using a $2 \mathrm{k} \times 2 \mathrm{k}$ Gatan CCD camera equipped with a post column Gatan Energy Filter (GIF), with an electron dose of 15 and 50 e $\AA^{-2}$ per image for $\mathrm{HAuCl}_{4}$ and $\mathrm{H}_{3} \mathrm{PO}_{4}$ infiltrated samples, respectively. For TEM observations, the membranes were embedded 
in EMS Epofix embedding resin and cured at $70^{\circ} \mathrm{C}$ for 1 hour. The embedded sample was cross cut using a Reichert-Jung Ultracut-E ultramicrotome set to 50 or $70 \mathrm{~nm}$ thickness. The cross sections were transferred to a continuous carbon 200 square mesh copper grid by using an EMS perfect loop.

\section{Anhydrous proton conduction}

Electrochemical impedance spectroscopy (EIS) was recorded on an Autolab potentiostat equipped with hot stage (accuracy: $\pm 0.01{ }^{\circ} \mathrm{C}$ ) in a frequency range from $1 \mathrm{~Hz}$ to $1 \mathrm{MHz}$ (applied voltage: $10 \mathrm{mV}$ ). Gold electrodes of a set area $\left(0.28 \mathrm{~cm}^{2}\right)$ were applied on both sides of the polymeric films. The conductivities were measured as a function of temperature between room temperature $\left(22^{\circ} \mathrm{C}\right)$ and $170^{\circ} \mathrm{C}$ with 5 ${ }^{\circ} \mathrm{C}$ intervals. The polymer films were vacuum dried overnight at room temperature and annealed at $120^{\circ} \mathrm{C}$ for 20 min before starting the measurement. The impedance spectrum can be modelled as an equivalent circuit and divided into imaginary $\left(Z^{\prime \prime}\right)$ and real $\left(Z^{\prime}\right)$ components. The resistance $\left(R_{b}\right)$ was estimated from the intersection of the real axis $\left(Z^{\prime}\right)$ and the semicircle of the impedance spectrum. The proton conductivities $\sigma\left(\mathrm{S} \mathrm{cm}^{-1}\right)$ are calculated using the following equation:

$$
\sigma=\frac{d}{R_{b} A}
$$

Where $d(\mathrm{~cm})$ is the thickness of the film, $A\left(\mathrm{~cm}^{2}\right)$ is the area of the film and $R_{b}(\Omega)$ is the resistance of the sample to conduction.

\section{Results and discussion}

\section{Preparation and characterization of the monomer mixtures}

To prepare the 2D nanoporous polymer containing cationic pores, first the hydrogen bonded complex of reactive mesogen 6SzMA and porogen 6-hexyloxybenzoic acid (6OB), 6SzMA•6OB, was studied in detail (Figure S1a). FTIR spectra were taken from both compounds and the 1:1 complex to study the hydrogen bonding (Figure S1b). $60 \mathrm{~B}$ displays a broad $-\mathrm{OH}$ band at $3000 \mathrm{~cm}^{-1}$ overlapping with the $\mathrm{sp}^{3}$ hybridized $\mathrm{C}-\mathrm{H}$ bands $\left(2860\right.$ and $\left.2930 \mathrm{~cm}^{-1}\right)$. The absence of the broad signal at $3000 \mathrm{~cm}^{-1}$ in the $65 \mathrm{SMA} \cdot 60 \mathrm{~B}$ spectrum and the presence of two new broad peaks centered at $1900 \mathrm{~cm}^{-1}$ and 2480 $\mathrm{cm}^{-1}$ and a band at $1705 \mathrm{~cm}^{-1}$, attributed to hydrogen bonded $\mathrm{O}-\mathrm{H}$ vibrations, confirm the formation of hydrogen bonds between $60 \mathrm{~B}$ and the 6SzMA. ${ }^{32}$ Differential scanning calorimetry (DSC) revealed that 6SzMA-60B exhibits various liquid crystal transitions (Figure S1c). By polarized optical microscopy (POM) the mesophases were identified by slowly cooling from the isotropic phase (Figure S1d-g). The $1: 1$ complex forms a smectic $A(\mathrm{SmA})$ mesophase at $140^{\circ} \mathrm{C}$. Upon further cooling a smectic $\mathrm{C}(\mathrm{SmC})$ mesophase is observed from 119 to $110{ }^{\circ} \mathrm{C}$. Two much higher order tilted smectic mesophases are observed from $80^{\circ} \mathrm{C}$ to $62{ }^{\circ} \mathrm{C}$ and from $62{ }^{\circ} \mathrm{C}$ to $-4{ }^{\circ} \mathrm{C}$, where after crystallization sets in. Subsequently, 6SzMA•60B mixtures containing various amounts of cross-linker ( $C L$, Figure 1a) were studied. The addition of $\mathrm{CL}$ led to changes in the phase behavior of the monomer 1:1 mixture. Increasing the amount of $\mathrm{CL}$ resulted in a decreased clearing temperature and the disappearance of tilted smectic mesophases. For example, when $50 \mathrm{wt} \% \mathrm{CL}$ is used, upon cooling from the isotropic state, a narrow nematic mesophase is observed at $119^{\circ} \mathrm{C}-117^{\circ} \mathrm{C}$ (Figure S2a), a SmA mesophase from 117 ${ }^{\circ} \mathrm{C}$ to $59{ }^{\circ} \mathrm{C}$ (Figure S2b), and a smectic B (SmB) mesophase from 59
${ }^{\circ} \mathrm{C}$ to $-15{ }^{\circ} \mathrm{C}$ (Figure S2c) indicated by the slightly more homogeneous texture and the observation of transition bands perpendicular to the molecular director at $\mathrm{T}_{\mathrm{SmA} A \mathrm{SmB}}$ by polarized optical microscopy.

\section{Preparation and characterization of LCNs}

Homogeneous planar aligned LCN films with a defined thickness (20 $\mu \mathrm{m}$ ) were prepared by photopolymerizing the $6 \mathrm{SzMA} \cdot 6 \mathrm{OB} \cdot \mathrm{CL}$ monomers (Figure 1a) in home-made LC cells. After UV irradiation for $10 \mathrm{~min}$, the samples were polymerized as was confirmed by the disappearance of the peaks at $1640 \mathrm{~cm}^{-1}$ ( $\mathrm{C}=\mathrm{C}$ stretching vibration), $1410 \mathrm{~cm}^{-1}\left(-\mathrm{CH}_{2}\right.$ deformation vibration), and $1290 \mathrm{~cm}^{-1}(-\mathrm{CH}$ rocking vibration) in the FTIR spectrum (Figure S3). The order and alignment of the material was studied by POM and $x$-ray scattering measurements. From the small angle region of the pristine polymer film x-ray diffractogram, one can see that the smectic layer spacing is strongly influenced by the amount of cross-linker. For films containing 10,25 , and $50 \mathrm{wt} \% \mathrm{CL}$, a layer spacing of 4.05 ( $\mathrm{q}=1.55 \mathrm{~nm}^{-}$ 1), $4.40\left(q=1.43 \mathrm{~nm}^{-1}\right)$ and $4.82 \mathrm{~nm}\left(\mathrm{q}=1.30 \mathrm{~nm}^{-1}\right)$ was found, respectively (Figure 2 ), which can be directly linked to the $d$-spacing of the individual compounds and their respective amounts (Figure $2 \mathrm{e}$, dashed line)..$^{33-35}$ The polymer film containing $10 \mathrm{wt} \% \mathrm{CL}$ displays a weak small angle signal that is split-up and is extremely broad, which suggests the demixing of $6 \mathrm{SzMA} \bullet 60 \mathrm{~B}$ and $\mathrm{CL}$ occurs. The wide angle area of the $2 \mathrm{D} x$-ray scattering patterns (Figure $2 \mathrm{a}$-c) show lobes located at $\mathrm{q} \approx 14 \mathrm{~nm}^{-1}$ which become narrower and more intense with increasing cross-link density suggesting that the orientational order is increasing (Figure $2 \mathrm{f}$ ). ${ }^{33}$ The radial integration curves were fitted from $\vartheta=-0.5 \pi$ to $0.5 \pi$ with the maximum intensity located at $\vartheta=0$ (Figure 2f) giving orientation order parameters of $0.90,0.73$, and 0.58 for the LCNs containing 50,25 , and $10 \mathrm{wt} \% \mathrm{CL} .{ }^{36}$
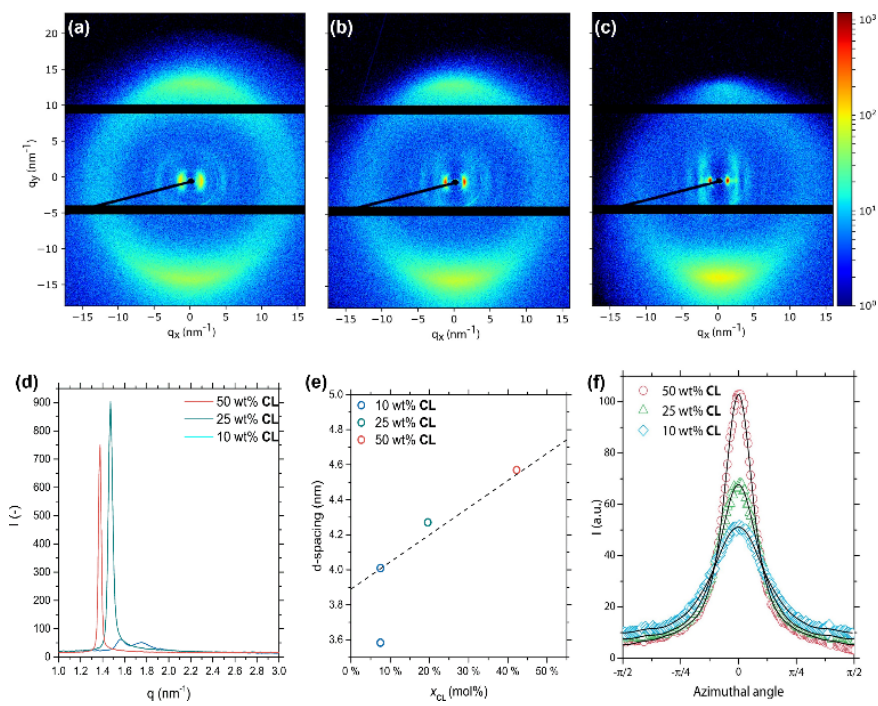

Figure 2 Structural characterization of the pristine polymer films. (a-c) 2D x-ray diffractograms of LCNs containing 10,25 , and $50 \mathrm{wt} \% \mathrm{CL}$, respectively. N.B. The visible asymmetry and dark region is caused by the partial blocking of the scattered $\mathrm{x}$-rays by the sample holder. (d) Azimuthal integration of the small angle region of the $x$-ray diffractograms obtained from MAXS measurements. (e) $d$-spacing as a function of $x_{C L}$. (f) Radial integration of the wide angle signal $\left(q \approx 14 \mathrm{~nm}^{-1}\right.$ ). 
Preparation and characterization of the nanoporous polymers by template removal

In order to obtain nanoporous polymers, the $60 \mathrm{~B}$ template was removed from the LCN (Figure S4a). In the FTIR spectrum, signals at 2500,1920 , and $1680 \mathrm{~cm}^{-1}$ disappeared, indicating the cleavage of the hydrogen bonds. Furthermore, the relative decrease in intensity of the sp $\mathrm{sp}^{3} \mathrm{C}-\mathrm{H}$ bonds located at 2930 and $2855 \mathrm{~cm}^{-1}$ indicate that aliphatic material (6OB tail) is removed from the LCN (Figure 3a). The quantitative removal of $60 B$ was confirmed by weighing small pieces of film before and after the treatment. Indeed, the weight loss measured corresponds to the initial mass of $60 \mathrm{~B}$ added to the mixture, as seen in Figure $3 \mathrm{~b}$. The macroscopic dimensional changes of the film after removal of $60 \mathrm{~B}$ and drying of the film were also investigated. Perpendicular to the molecular director, a small expansion (1.8 - 3.4\%) was observed while parallel to the molecular director a more significant contraction of the film was noticed (Figure S4b). The contraction is highly dependent on the concentration $\mathrm{CL}$ present $\left(x_{C L}, w t \%\right)$, and for the films containing 10, 25 and $50 \mathrm{wt} \% \mathrm{CL}$ a contraction of 18,11 and $7 \%$ was measured, respectively.
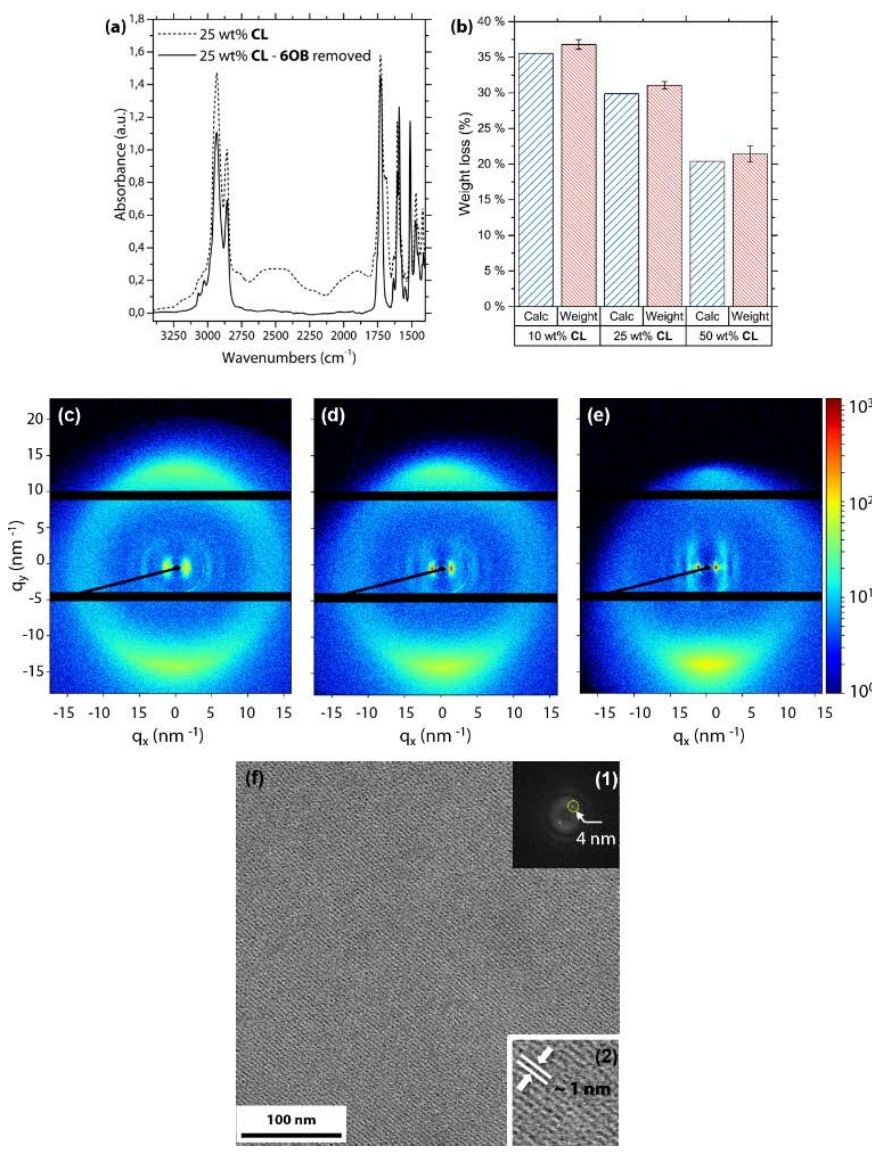

Figure 3 Removal of the $60 \mathrm{~B}$ template. (a) FTIR spectra of a pristine LCN containing 25 wt\% CL (short-dash line) and the same film after removing 6OB template (solid line). (b) Calculated and measured relative weight loss of the samples after removing the $60 \mathrm{~B}$ template of samples containing $10,25,50 \mathrm{wt} \% \mathrm{CL}$. 2D $\mathrm{x}$-ray diffractograms of nanoporous LCNs containing (c) 10 , (d) 25 , and (e) $50 \mathrm{wt} \% \mathrm{CL}$, respectively. (f) High magnification TEM micrograph of the central area of the $50 \mathrm{wt} \% \mathrm{CL}$ film. Inset 1: FFT of the micrograph. Inset 2: The zoom-in image of the layers.

XRD measurements were also performed to investigate the impact of the $60 \mathrm{~B}$ removal on the microscopic structure of the material (Figure 3c-e). For the sample containing only $10 \mathrm{wt} \% \mathrm{CL}$, no layer spacing could be observed indicating that the lamellar structure within the LCN was lost. A $d$-spacing of 3.98 and $4.47 \mathrm{~nm}$ was obtained for the materials consisting of 25 and 50 wt\% CL, respectively, corresponding to a decrease in layer spacing of 9.5 and $7.2 \%$. These numbers indicated that the removal of the $60 \mathrm{~B}$ led to a partial disorder of the microscopic lamellar structure. Interestingly, the $d$-spacing of the film containing $50 \mathrm{wt} \% \mathrm{CL}$ is roughly twice the length of a 6SzMA moiety $(2.26 \mathrm{~nm})$, indicating a head-to-head organization while the sample containing $25 \mathrm{wt} \% \mathrm{CL}$, has a spacing smaller than the length of two 6SzMA moieties, revealing a slight interdigitation. These results show that for cross-link density above $25 \mathrm{wt} \%$, the internal lamellar structure can be preserved despite a decrease of the orientational order of the materials after removal of the $60 B$ moiety. From the radial integration of the wide angle XRD signal (Figure S5), the orientational order parameter was estimated, and values of $0.37,0.48$, and 0.78 for 10,25 , and $50 \mathrm{wt} \% \mathrm{CL}$, respectively, were obtained. TEM image of the $6 \mathrm{SzMA} \cdot 60 \mathrm{~B}$ LCN with $50 \mathrm{wt} \% \mathrm{CL}$ film was taken to visualize the nanostructures. Auric chloride $\left(\mathrm{HAuCl}_{4}\right)$ was used as staining agent as it will bind to the pyridyl moieties (Figure $3 f$ ). After the infiltration, first transmission $x$ ray diffraction measurements (Figure S6) revealed that the position of the signals originating from the lamellar spacing did not change a lot compared to the nanoporous polymer film ( $q=1.50 \mathrm{~nm}^{-1}, \mathrm{~d}=4.2$ $\mathrm{nm}$ ). Subsequently, the film was ultramicrotomed perpendicular to the molecular director and $\sim 50 \mathrm{~nm}$ thick cross-sections were examined by transmission electron microscopy revealing a regular lamellar organization with straight and well-defined layers. From the FFT-transformed micrograph (Figure $3 f$, inset 1) a well-defined spacing of $4 \mathrm{~nm}$ was found, which is in agreement with the distance found earlier by $x$-ray diffraction. The zoom-in TEM image shows the thickness of the $\left(\mathrm{AuCl}_{4}\right)^{-}$layers is $\sim 1 \mathrm{~nm}$ (Figure 3f, inset 2). This data shows that $2 \mathrm{D}$ nanoporous polymer films are obtained having straight and uniform pores.

\section{Fabrication of cationic pores and anhydrous proton conduction}

As an important potential application of this well-defined nanoporous material is in proton conduction (e.g. fuel cells), the proton conducting properties of the material were investigated. Since the pyridyl pore surface in the nanoporous LCN is basic, phosphoric acid, a popularly used proton conducting component ${ }^{28}$ is immobilized into the anisotropic lamellae. Before exposing the nanoporous LCNs to the phosphoric acid, the pKa of the pyridine was determined to identify under which conditions cationic pores are formed. Visually, a colour change from nearly colourless to bright yellow was observed for the films held in low $\mathrm{pH}$ solutions (typically $<\mathrm{pH} 3$ ), indicating the protonation of the stilbazole. ${ }^{37}$ After 16 hours, the films were removed from the solutions and measured by FTIR to obtain quantitative information (Figure S7). A broad peak cantered at $2600 \mathrm{~cm}^{-1}$ (attributed to the $\mathrm{N}-\mathrm{H}$ bond) appeared and was followed to monitor the protonation. Materials containing 10 and 25 wt\% $\mathrm{CL}$ had a similar pKa ( 3.1), while for the material containing 50 $w t \% \mathrm{CL}$, a pKa of roughly 1.8 was estimated. It is known from literature that stilbazole derivatives have a pKa of 4.7. ${ }^{38}$ This suggests that the cross-linked network influences the acidity of the pyridyl nitrogen, whereby stronger networks require stronger acids to protonate the stilbazole. Both films containing $10 \mathrm{wt} \%$ and $25 \mathrm{wt} \%$ CL are easily protonated and display a high proton capacity (2.32 and 
$1.78 \mathrm{mmol} \mathrm{g}^{-1}$, respectively) as compared to the $50 \mathrm{wt} \% \mathrm{CL}$ sample $\left(1.05 \mathrm{mmol} \mathrm{g}^{-1}\right)$. The mechanical and structural properties of the nanoporous LCNs film containing $10 \mathrm{wt} \% \mathrm{CL}$ were poor compared to the $25 \mathrm{wt} \% \mathrm{CL}$ films. Therefore, based on these results, only the 25 wt $\%$ CL films were used for proton conductivity.

Immobilization of the phosphoric acid in the pores was achieved by exposing the nanoporous LCN films to a $0.1 \mathrm{M} \mathrm{H}_{3} \mathrm{PO}_{4}$ solution in either pure THF or a 1:1 (v:v) THF/water mixture. After exposure, the obtained films were examined using transmission FTIR spectroscopy (Figure S8a). A broad peak was observed ranging from $3400 \mathrm{~cm}^{-1}$ to $2000 \mathrm{~cm}^{-1}$, originating from the stilbazolium $\mathrm{N}^{+}-\mathrm{H}$ and phosphoric acid $-\mathrm{OH}$ vibrations. Furthermore, the films that contain phosphoric acid using pure THF as solvent show a higher absorbance than films where a THF/water mixture was used, indicating a higher degree of occupation. Figure S8b shows that when using pure THF, and assuming only electrostatic interactions $\left(1.78 \mathrm{mmol} \mathrm{g}^{-1}\right)$, an occupation level of 2.54 eq. $\mathrm{H}_{3} \mathrm{PO}_{4}$ was obtained. It is known that phosphoric acid can form strong intermolecular hydrogen bonds in solution, therefore hydrogen bonded $\mathrm{H}_{3} \mathrm{PO}_{4}$ clusters could be incorporated, explaining the high degree of occupation. When a 1:1 (v:v) THF/ $\mathrm{H}_{2} \mathrm{O}$ mixture was used, an occupation level of 1.06 eq. $\mathrm{H}_{3} \mathrm{PO}_{4}$ was obtained. This indicates that the addition of water, leads to a lower degree of occupation by promoting the dissociation of the hydrogen bonds between $\mathrm{H}_{3} \mathrm{PO}_{4}$ molecules in solution. A TEM image of the 2.54 eq. $\mathrm{H}_{3} \mathrm{PO}_{4}$ film (with $25 \mathrm{wt} \% \mathrm{CL}$ ) was taken to visualize the nanostructures (Figure 4a). Well-organized structures having $\mathrm{H}_{3} \mathrm{PO}_{4}$ layers of about $1 \mathrm{~nm}$ were again visible. However, it should be noted that also less ordered areas (Figure S9) were found in the film. The latter could also be due to the lower contrast of $\mathrm{H}_{3} \mathrm{PO}_{4}$ compared to the $\mathrm{HAuCl}_{4}$ infiltrated films.
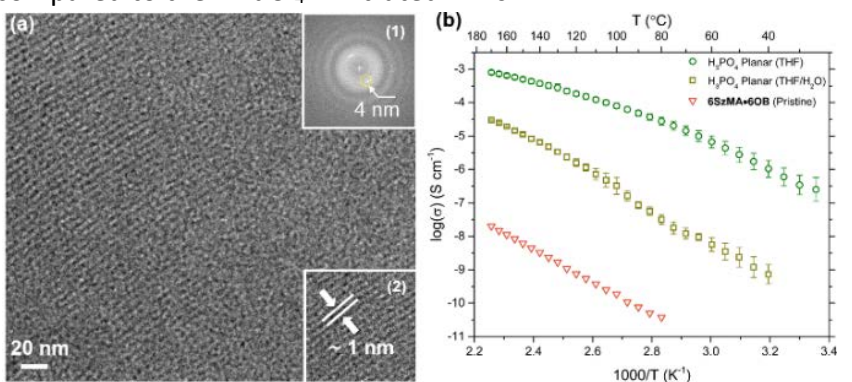

(c)

(d)
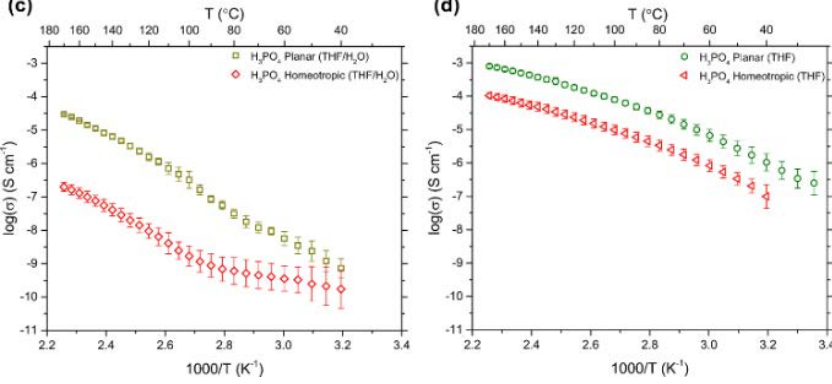

Figure 4 Proton conduction of $\mathrm{H}_{3} \mathrm{PO}_{4}$ infiltrated films containing $25 \mathrm{wt} \% \mathrm{CL}$. (a) High magnification TEM micrograph of the 2.54 eq. $\mathrm{H}_{3} \mathrm{PO}_{4}$ infiltrated film. Inset 1: FFT of the micrograph. Inset 2: The zoom-in image of the layers. (b) Anhydrous proton conduction in a planar aligned pristine (6SzMA•6OB) film (orange open triangles), and planar aligned nanoporous films containing 1.06 eq. $\mathrm{H}_{3} \mathrm{PO}_{4}$ (dark green open squares), and 2.54 eq. $\mathrm{H}_{3} \mathrm{PO}_{4}$ (light green open circles), respectively. (c) Anhydrous proton conduction in planar (dark green open squares), and homeotropic aligned (red open diamonds) nanoporous films containing 1.06 eq. $\mathrm{H}_{3} \mathrm{PO}_{4}$. (d) Anhydrous proton conduction in planar (light green open squares), and homeotropic aligned (red open triangles) nanoporous films containing 2.54 eq. $\mathrm{H}_{3} \mathrm{PO}_{4}$.
The proton conductivity was measured using electrochemical impedance spectroscopy (EIS). The impedance spectrum resembles the equivalent circuits containing an interfacial capacitance $\left(C P E_{1}\right)$, the sample field capacitance $\left(C P E_{2}\right)$, and the sample resistance $\left(R_{b}\right)$ (Figure S10). At each given temperature, the resistance $R_{b}$ was estimated from the intersection of the real axis $\left(Z^{\prime}\right)$ and the semicircle of the impedance spectrum. The proton conduction of planar aligned LCNs containing 1.06 eq. $\mathrm{H}_{3} \mathrm{PO}_{4}, 2.54$ eq. $\mathrm{H}_{3} \mathrm{PO}_{4}$, and the initial 6OB porogen are depicted Figure $4 \mathrm{~b}$. The conductivity increases with increasing temperature. The Arrhenius behavior (linear on the log $(\sigma)$ versus $\mathrm{T}^{-1}(\mathrm{~K})$ scale) of this curve implies that the proton conduction is dominated by the "hopping" (Grotthuss) mechanism. ${ }^{39,40}$ The conductivity of $\mathrm{LCNs}$ containing $1.06 \mathrm{eq}$. and 2.54 eq. $\mathrm{H}_{3} \mathrm{PO}_{4}$ reaches a maximum conductivity of about $3 \times 10^{-5} \mathrm{~S} \mathrm{~cm}^{-1}$ and $8 \times 10^{-4} \mathrm{~S} \mathrm{~cm}^{-1}$ at $170{ }^{\circ} \mathrm{C}$, respectively. This is a great, more than four orders of magnitude, enhancement compared with the 6SzMA•6OB LCN, which reaches a maximum conductivity of only $2 \times 10^{-8} \mathrm{~S} \mathrm{~cm}^{-1}$. The values are higher than other reported LC based nanoporous polymer materials ${ }^{41-44}$. The values are, however, two to three orders of magnitude lower than the best performing anhydrous proton conductive materials, i.e. $\mathrm{H}_{3} \mathrm{PO}_{4}$ based polymers, ${ }^{45,46}$ reported so far.

To demonstrate that the film benefits from the straight pores through the thickness of the film, homeotropic aligned films that have the pores oriented parallel to the electrodes were prepared as well. A comparable degree of occupation was achieved using the $\mathrm{H}_{3} \mathrm{PO}_{4}$ infiltration methods mentioned before. Figure $4 \mathrm{c}$ shows the proton conduction in both planar and homeotropic aligned films containing 1.06 eq. of $\mathrm{H}_{3} \mathrm{PO}_{4}$. At high temperatures, the proton conduction in homeotropic aligned films was two orders of magnitude lower than when using planar aligned films, indicating that the orientation of the pores contributes significantly to the high conductivity. In the homeotropic aligned films, the polymer layers act as insulating layers, hindering the traveling of protons and revealing that the transport of protons through straight pores is preferred, as anticipated. Peculiarly, the temperature dependence of the conductivity does not show Arrhenius behavior. At low temperature, only a moderate increase in conduction is observed. This is most likely because the protons have to cross the polymeric layers as mentioned above. However, once passed the $\sim 100{ }^{\circ} \mathrm{C}$, the mobility increases so the protons can more easily cross this barrier. Thereafter, the temperature dependence of the conduction behavior is similar to the planar sample, yet, at lower conductivity. The proton conduction of the homeotropic films containing 2.54 eq. of $\mathrm{H}_{3} \mathrm{PO}_{4}$ (Figure 4d) was measured too. Despite a higher conductivity for the planar sample, the difference in proton conductivity with the homeotropic aligned films was substantially smaller than when 1.06 eq. $\mathrm{H}_{3} \mathrm{PO}_{4}$ were used. In contrast to the films with a lower $\mathrm{H}_{3} \mathrm{PO}_{4}$ occupation as discussed before, here both films show the same temperature dependence curve with a one order of magnitude difference in conductivity, indicating that the orientation of the anisotropic pores play a less important role. It is expected that the excess of phosphoric acid facilitates the transport of protons across the polymeric layers.

\section{Conclusions}


Cationic 2D nanoporous polymers have been prepared by a template method based on supramolecular smectic liquid crystals. It was found that the layered structure was maintained after template removal when 25 wt\% or more cross-linker was used. This facile method can be applied to other porogens and cross-linkers to tune the pore size by a modular approach. Proton conductivity measurements show that cationic nanoporous materials exhibit a high and anisotropic proton conductivity, making them appealing as polymer electrolytes in for example fuel cells. The H3PO4 interacts with the positively chargeable pyridine groups resulting in ordered protic nanopores that facilitates the proton conduction. Furthermore, the decrease in conductivity in homeotropic oriented films shows that the orientation of the $2 \mathrm{D}$ plane plays an important role. Our results show that 2D cationic nanoporous polymers can be fabricated with appealing functional properties. It is foreseen that also $\mathrm{pH}$ independent cationic nanoporous polymers can be fabricated by alkylation of the pyridine units. Such type polymers are interesting to separate, adsorb or sense anions and negatively charged molecules.

\section{Conflicts of interest}

There are no conflicts to declare.

\section{Acknowledgements}

This research forms part of the research program of the Dutch Polymer Institute (DPI), project 776. Ting Liang is financially supported by China Scholarship Council (CSC). The authors would like to thank Dick Broer for the fruitful discussions and Dr. Lu Gao for the EIS measurements and discussion.

\section{Notes and references}

1 X. Lu, G.; Zhao, Nanoporous Materials Science and Engineering, Imperial College Press, London, 2004.

2 R. Dawson, A. I. Cooper and D. J. Adams, Progress in Polymer Science, 2012, 37, 530-563.

3 P. W. Majewski, M. Gopinadhan and C. O. Osuji, Soft Matter, 2013, 9, 7106-7116.

4 P. R. Sajanlal, T. S. Sreeprasad, A. K. Samal and T. Pradeep, Nano Reviews \& Experiments, 2017, 2, 5883-5944.

5 M. Yoon, K. Suh, H. Kim, Y. Kim, N. Selvapalam and K. Kim, Angewandte Chemie - International Edition, 2011, 50, 7870-7873.

6 M. J. Park and N. P. Balsara, Macromolecules, 2010, 43, 292-298.

7 J. H. Lee, Sensors and Actuators, B: Chemical, 2009, 140, 319-336.

8 M. Thommes, Chemie-Ingenieur-Technik, 2010, 82, 10591073.

9 Y. Sone, Journal of The Electrochemical Society, 1996, 143, 1254-1259.

10 J. Luo, A. H. Jensen, N. R. Brooks, J. Sniekers, M. Knipper, D. Aili, Q. Li, B. Vanroy, M. Wübbenhorst, F. Yan, L. Van
Meervelt, Z. Shao, J. Fang, Z. H. Luo, D. E. De Vos, K. Binnemans and J. Fransaer, Energy Environ. Sci., 2015, 8, 1276-1291.

11 X. Chen, H. Tang, T. Putzeys, J. Sniekers, M. Wübbenhorst, K. Binnemans, J. Fransaer, D. E. De Vos, Q. Li and J. Luo, J. Mater. Chem. A, 2016, 4, 12241-12252.

A. Schenning, Y. C. Gonzalez-Lemus, I. K. Shishmanova and D. J. Broer, Liquid Crystals, 2011, 38, 1627-1639.

13 T. Kato, Angewandte Chemie - International Edition, 2010, 49, 7847-7848.

14 D. L. Gin, X. Lu, P. R. Nemade, C. S. Pecinovsky, Y. Xu and M. Zhou, Advanced Functional Materials, 2006, 16, 865878.

15 T. Kato, J. Uchida, T. Ichikawa and T. Sakamoto, Angewandte Chemie International Edition, 2018, 57, 43554371.

16 D. J. Broer, C. M. W. Bastiaansen, M. G. Debije and A. P. H. J. Schenning, Angewandte Chemie - International Edition, 2012, 51, 7102-7109.

T. Kato and J. Frechet, Journal of the American Chemical Society, 1989, 111, 8533-8534.

I. Gracia, P. Romero, J. L. Serrano, J. Barberá and A. Omenat, 2017, 5, 2033-2042.

C. Li, J. Cho, K. Yamada, D. Hashizume, F. Araoka, H. Takezoe, T. Aida and Y. Ishida, Nature Communications, 2015, 6, 8418(1-9).

K. Kishikawa, A. Hirai and S. Kohmoto, Chemistry of Materials, 2008, 20, 1931-1935.

21 H. K. Lee, H. Lee, Y. H. Ko, Y. J. Chang, N. K. Oh, W. C. Zin and O. Kim, Angewandte Chemie - International Edition, 2001, 40, 2669-2671.

O. Ikkala and G. ten Brinke, Chemical Communications, 2004, 19, 2131-2137.

X. Feng, M. E. Tousley, M. G. Cowan, B. R. Wiesenauer, S. Nejati, Y. Choo, R. D. Noble, M. Elimelech, D. L. Gin and C. O. Osuji, ACS Nano, 2014, 8, 11977-11986.

C. L. Gonzalez, C. W. M. Bastiaansen, J. Lub, J. Loos, K. Lu, H. J. Wondergem and D. J. Broer, Advanced Materials, 2008, 20, 1246-1252. 461-468. Osuji, ACS Nano, 2017, 11, 3911-3921.

K. Kishikawa, A. Hirai and S. Kohmoto, Chemistry of Materials, 2008, 20, 1931-1935. L. Vilčiauskas, M. E. Tuckerman, G. Bester, S. J. Paddison and K. D. Kreuer, Nature Chemistry, 2012, 4, 461-466. E. A. W. B. D. Shaw, Journal of the Chemical Society (Resumed), 1933, 77-79.

M. C. Chiang and W. H. Hartung, Journal of Organic Chemistry, 1945, 10, 21-25.

J. E. Stumpel, D. Liu, D. J. Broer and A. P. H. J. Schenning, Chemistry - A European Journal, 2013, 19, 10922-10927. T. Kato, J. M. J. Fréchet, T. Uryu, F. Kaneuchi and C. Jin, Liquid Crystals, 2006, 33, 1429-1437.

S. Diele, Berichte der Bunsengesellschaft für physikalische Chemie, 1993, 97, 1326-1336. 
34 N. Kapernaum, C. Scott Hartley, J. C. Roberts, R. P. Lemieux and F. Giesselmann, Beilstein Journal of Organic Chemistry, 2009, 5, 4-11.

35 N. Kapernaum, F. Knecht, C. S. Hartley, J. C. Roberts, R. P. Lemieux and F. Giesselmann, Beilstein Journal of Organic Chemistry, 2012, 8, 1118-1125.

P. Davidson, D. Petermann and A. M. Levelut, Journal de Physique II, 1995, 5, 113-131.

37 G. Favaro, U. Mazzucato and F. Masetti, The Journal of Physical Chemistry, 1973, 77, 601-604.

38 G. Giacometti, U. Mazzucato and S. Parolini, Tetrahedron Letters, 1964, 5, 3733-3737.

39 W. J. Liang, S. J. Hsieh, C. Y. Hsu, W. F. Chen and P. L. Kuo, Journal of Polymer Science Part B: Polymer Physics, 2006, 44, 2135-2144.

40 J. Luo, O. Conrad and I. F. J. Vankelecom, J. Mater. Chem. A, 2013, 1, 2238-2247.

41 T. Liang, H. P. C. Van Kuringen, D. J. Mulder, S. Tan, Y. Wu, Z. Borneman, K. Nijmeijer and A. P. H. J. Schenning, ACS Applied Materials and Interfaces, 2017, 9, 35218-35225.

42 A. Concellon, T. Liang, A. Schenning, J. L. Serrano, P. Romero and M. Marcos, Journal of Materials Chemistry C, 20178, 6, 1000-1007.

43 T. Kobayashi, T. Ichikawa, T. Kato and H. Ohno, Advanced Materials, 2017, 29, 1604429(1-6).

$44 \quad X$. Yang, S. Tan, T. Liang, B. Wei and Y. Wu, J. Membr. Sci., 2017, 523, 355-360.

45 S. Yuan, X. Guo, D. Aili, C. Pan, Q. Li and J. Fang, Journal of Membrane Science, 2014, 454, 351-358.

46 J. Yang, Y. Wang, G. Yang and S. Zhan, International Journal of Hydrogen Energy, 2018, 43, 8464-8473. 